\title{
Atuais Reformas Educacionais para o Ensino Médio no Brasil.
}

\author{
Current Educational Reforms for High Scool in Brazil \\ Reformas Educativas Actuales para la Escuela Alta en Brasil
}

\author{
LARISSA DOS SANTOS ESTEVÃO \\ Universidade Federal de Pernambuco (UFPE)
}

\begin{abstract}
RESUMO: Esse artigo versa sobre as atuais reformas educacionais para o ensino médio no Brasil, onde sistematiza uma análise sobre a BNCC, o "Novo Ensino Médio" $e$ as DCNEM. É uma pesquisa de cunho bibliográfico e documental, fundamentada nos aportes teóricos do marxismo. Seus resultados evidenciam que as reformas estão fundamentadas no projeto educacional dos organismos internacionais, no qual a educação é entendida como caminho para o desenvolvimento econômico e social, sustentado pela TCH e da Sociedade do Conhecimento. O estudo permitiu compreender que a BNCC é posta como uma lei geral da educação, a qual todo o sistema educacional brasileiro precisa se ajustar. Essa reestruturação curricular é um catálogo de competências e babilidades (cognitivas/socioemocionais) a serem desenvolvidas, fundamentado numa concepção gerencialista, que visa controle, regulação e punição. Aprofunda o caráter de classe da educação brasileira, reproduzindo as desigualdades da sociedade capitalista no seio da escola, oficializando a dualidade estrutural.
\end{abstract}

\section{REFORMAS EDUCACIONAIS. BNCC. ENSINO MÉDIO.}

\begin{abstract}
This article concentrates on the current educational reforms for high school in Brazil, where it systematizes an analysis about the BNCC, "New High School" and DCNEM. It is a bibliographic and documentary research, based on the theoretical contributions of Marxism. The results of the research show that the various reforms are based on the educational project of international bodies, in which education is understood as a path to economic and social development, supported by the Theory of Human Capital and the Knowledge Society. The study allowed us to understand that BNCC is put as a general law of education, to which the entire Brazilian educational system needs to adjust. This curricular restructuring is a catalogue of competence and skills, both cognitive and socio-emotional, to be developed and based on a managerial conception, which aims at control, regulation and punishment. It also deepens the class character of Brazilian education, reproducing the inequalities of capitalist society within the school, officializing structural duality, its classdivision.
\end{abstract}

\section{EDUCATIONAL REFORMS. BNCC. HIGH SCHOOL.}

\footnotetext{
1 O presente estudo emerge de pesquisa de mestrado concluída no Programa de Pós-Graduação em Educação da Universidade Federal de Pernambuco intitulada "Imperialismo e Políticas Educacionais para o Ensino Médio no Brasil", desenvolvida na Linha de Pesquisa Política Educacional, Planejamento e Gestão da Educação e obteve apoio financeiro da Coordenação de Aperfeiçoamento de Pessoal de Nível Superior (CAPES).
} 


\begin{abstract}
RESUMEN: Este articulo trata de las reformas educativas actuales para la escuela secundaria en Brasil, donde sistematiza un análisis sobre BNCC, "Novo Ensino Médio" y DCNEM. Se trata de una investigación bibliográfica y documental, basada en las aportaciones teóricas del marxismo. Los resultados de la investigación muestran que las diversas reformas se basan en el proyecto educativo de las organizaciones internacionales, en el que la educación se entiende como un camino hacia el desarrollo económico y social, apoyado por la Teoría del Capital Humano y la Sociedad del Conocimiento. El estudio nos permitió entender que el BNCC se pone como una ley general de la educación, que todo el sistema educativo brasileño necesita ajustar. Esta reestructuración curricular es un catálogo de competencias y habilidades, tanto cognitivas como socioemocionales, a desarrollar y se basa en una concepción gerencial, que tiene como objetivo el control, la regulación y el castigo. También profundiza el carácter de clase de la educación brasileña, reproduciendo las desigualdades de la sociedad capitalista dentro de la escuela, convirtiéndola en la dualidad estructural oficial, su división clasista.
\end{abstract}

REFORMAS EDUCATIVAS. BNCC. EN LA SECUNDARIA.

\title{
Introdução
}

A eclosão da aguda crise estrutural do capitalismo, em 1970, trouxe consigo o colapso do regime de produção fordista-taylorista-keynesiano e seu Estado de bem-estar social ou welfare state. Este último havia garantido, no pós-guerra, um conjunto articulado de direitos sociais como educação, saúde, aposentadoria, como resposta às necessidades de acumulação e legitimação do sistema capitalista em muitos países industrializados, principalmente diante do avanço do socialismo. Com o seu fim, inicia-se uma reestruturação produtiva do capitalismo.

Essa nova reestruturação da produção e da acumulação do capital, chamada Acumulação Flexível, é marcada por uma crise estrutural sem precedentes - "crise de superprodução, existência de grande massa de capital financeiro especulativo (parasitário), choques incessantes entre as políticas imperialistas por meio das guerras comerciais, ofensivas neocolonizadoras sobre as semicolônias e a explosão do desemprego" (Souza, 2010, p. 149).

Esgotou-se o ciclo de crescimento do período pós-guerra e a resposta foi o desmonte do welfare state e o retorno ao Estado mínimo, intensificação da exploração e desregulamentação os direitos sociais e políticos dos trabalhadores para garantir maior liberdade de mercado e acumulação de capital.

$\mathrm{Na}$ América Latina, esse processo culminou no Consenso de Washington, em 1989, que impôs, através dos organismos internacionais de financiamento, as chamadas "reformas neoliberais"2, apontadas como necessárias aos países da América Latina e que implicavam em um programa de rigoroso equilibrio fiscal tendo como vetores um profundo corte nos gastos públicos - reformas administrativas, trabalhistas e previdenciárias -; uma rígida política monetária com o objetivo de estabilização; a desregulação dos mercados financeiro e do trabalho; a privatização radical e a abertura comercial (Saviani, 2013). Essas políticas, em vez de atenuar, como fora defendido, vêm reforçando a pobreza e a desigualdade mundial.

Souza (2010) destaca a importância de perceber quão sutil é a teoria do Estado mínimo, sendo esta é a chave para compreender esse debate. O Estado mínimo é caracterizado pela privatização generalizada e redução dos gastos públicos com as políticas sociais. Assim, o Estado perde sua capacidade de gerar emprego e dirimir a fome, entretanto, expande sua capacidade de dominação a partir do discurso do capital monopolista, onde a ideia central é que ele "perde" sua força de controle e se coloca nas mãos das grandes empresas, com a implementação do toyotismo e do avanço tecnológico.

Em face de todas essas mudanças implementadas para atender as necessidades e dar sobrevida ao sistema, o imperialismo passa a situar cada vez melhor a educação nas prioridades de seus organismos internacionais (Leher, 1999), pois passa a reconhecer a necessidade de controle do conhecimento e seu valor econômico e estratégico, transformando-o em mercadoria.

2 Segundo Silva (2017), a expressão "reformas neoliberais" é eufemismo para as imposições imperialistas. Assim como outras expressões - "neoliberalismo", "neocolonialismo", "globalização" e "mundialização" - são introduzidas por meio de significados amigáveis e negam "o papel hegemônico do Estado estadunidense, supondo que os ditames do mercado são algo exterior às políticas impostas pela sua rapinagem” (Souza, 2010, p. 38). 
A intervenção ideológica dos organismos internacionais nas políticas educacionais no Brasil, em especial do Banco Mundial, UNESCO e CEPAL de modo a administrar a pobreza a partir da centralidade da educação voltada para o crescimento e desenvolvimento econômico, tem implicado em uma série de medidas e reformas, ao logo dos anos, nas concepções e práticas que perpassam as questões educacionais e podem ser sintetizadas em: investimento em capital humano visando maior produtividade; foco em aprendizagens mínimas, com estreitamento e flexibilização curricular; desenvolvimento de habilidades socioemocionais; avaliação com foco em resultados de desempenho; responsabilização docente; privatização; reforça o caráter de classe do ensino.

São essas concepções vão permear também as atuais reformas educacionais, apenas com maior aprofundamento, vejamos.

Sob a visão consensual dos organismos internacionais a respeito da relação orgânica entre educação, crescimento econômico e desenvolvimento social, conferiu-se à Organização para Cooperação e Desenvolvimento Econômico (OCDE) o controle do desempenho escolar em nível internacional que passou a definir também o que seria qualidade de educação - ler, escrever, contar e ter noções básicas de ciências (Motta; Frigotto, 2017).

Com a justificativa da necessidade de melhorar o desempenho no Programa Internacional de Avaliação de Estudantes (PISA) e Índice de Desenvolvimento da Educação Básica (IDEB), instrumentos para mensurar a qualidade da educação, é que as atuais reformas na educação, em especial no ensino médio, estão sendo implementadas.

Notemos que após a publicação dos resultados do Sistema de Avaliação da Educação Básica (SAEB) de 2017, o então ministro da Educação, Rosseli Soares, afirmou que "O ensino médio brasileiro revelado pelo Saeb 2017 é um desastre. O desempenho insuficiente dos nossos estudantes, edição após edição da avaliação, confirma a importância das mudanças que trouxemos com o Novo Ensino Médio" (INEP, 2018, on-line).

Os dados do SAEB 2017, divulgados pelo INEP, de que trata o ex-ministro estão sistematizados nas Figuras 1 e 2 abaixo:

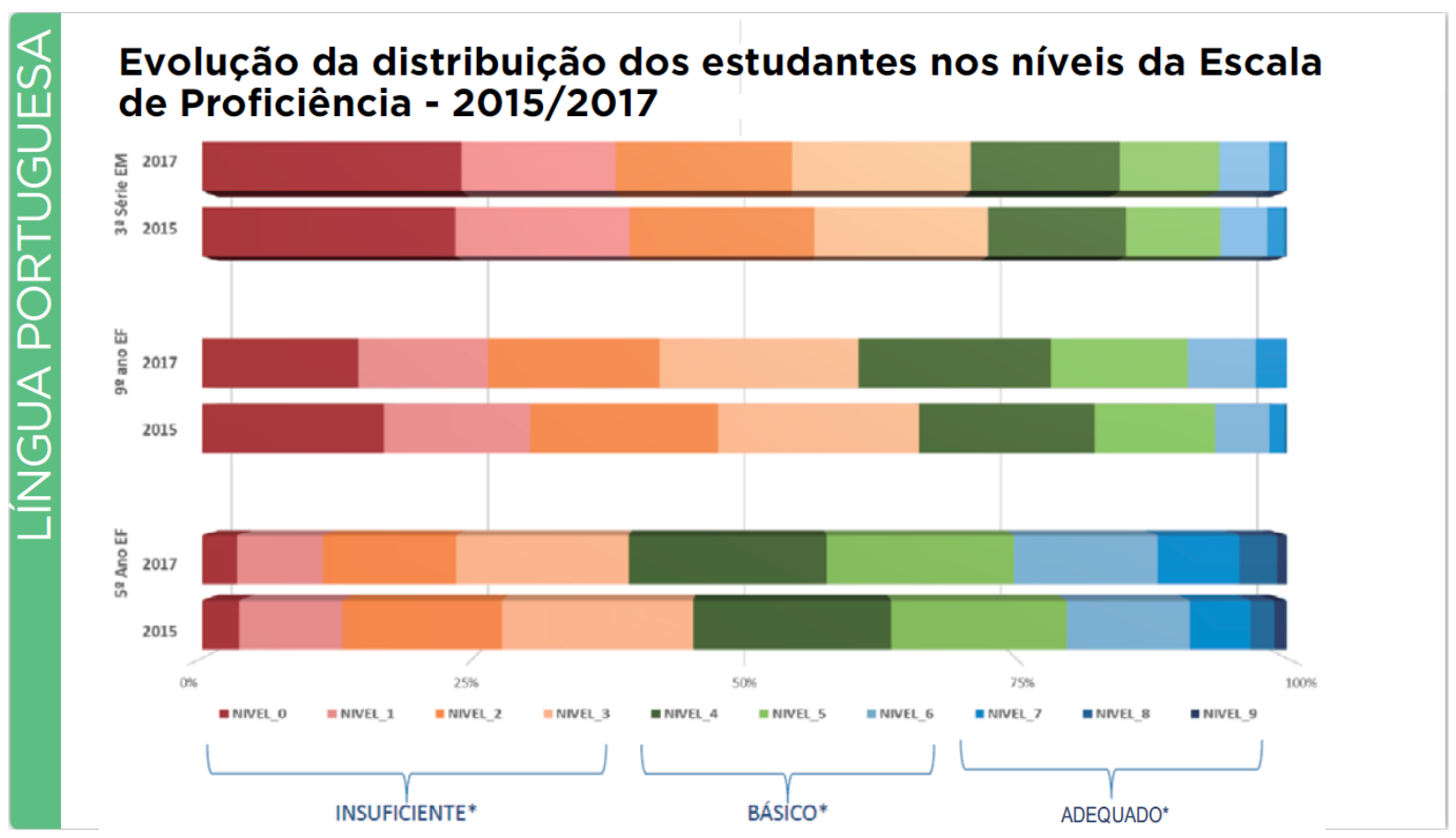

Figura 1: Evolução da distribuição dos estudantes nos níveis da Escala de Proficiência em Língua Portuguesa - 2015/2017

Fonte: INEP, 2018. 


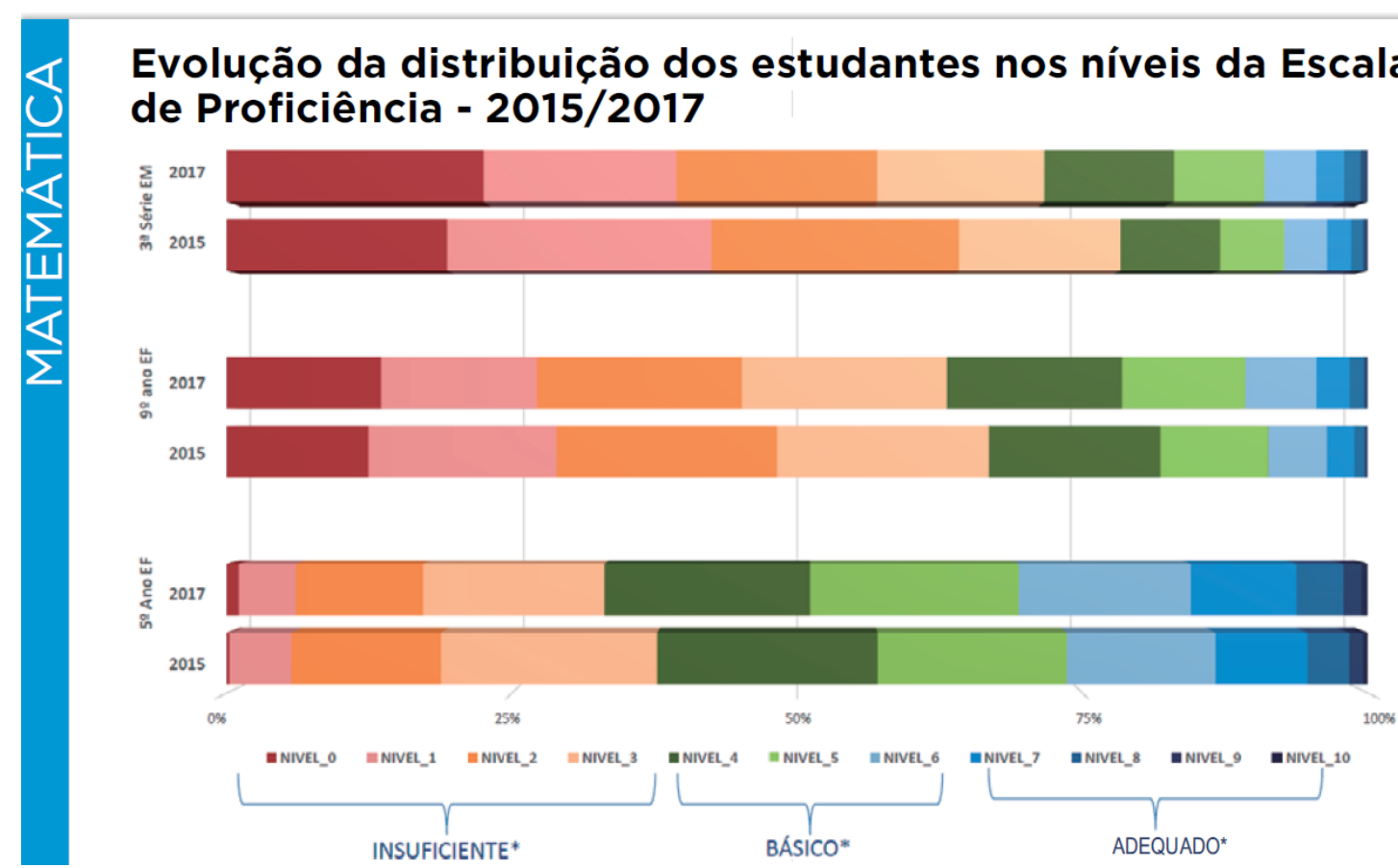

Figura 2: Evolução da distribuição dos estudantes nos níveis da Escala de Proficiência em Matemática $2015 / 2017$

Fonte: INEP, 2018.

Como podemos observar, tanto em Língua Portuguesa como em Matemática quase $75 \%$ dos estudantes tem desempenho insuficiente. Todavia, ao contrário de qualquer constrangimento que esses dados deveriam causar na pessoa que é responsável pela educação em nosso país, o então ministro fez questão de propagar a lamentável situação em que a mesma se encontra, sendo ainda reforçado pela então presidente do Instituto Nacional de Estudos e Pesquisas Educacionais Anísio Teixeira (INEP) e autora da matriz de referência do SAEB na década de 1990, que ressalta que o ensino médio pouco tem agregado ao desenvolvimento cognitivo dos estudantes e sua baixa qualidade tem prejudicado a formação para o mercado de trabalho e atrasado o desenvolvimento social e econômico do Brasil, sendo necessárias soluções inovadoras.

Lamentavelmente os resultados não registram ganhos de aprendizagens das nossas crianças e jovens. O Saeb 2017 evidencia, mais uma vez, a urgência da implantação e do apoio a revolucionários programas iniciados pelo Novo Ensino Médio, pela Base Nacional Comum Curricular (BNCC), o Mais Alfabetização, e o Ensino em tempo integral, para citar só alguns. É desalentador o confronto com esses resultados (INEP, 2018, on-line).

Freitas (2018c) chama atenção para o fato de que "Os resultados da avaliação do SAEB 2017 foram divulgados com uma mudança no critério de distribuição das pontuações dos alunos na escala de proficiência. Isso tornou mais difícil para um aluno ser classificado como 'proficiente' ou com 'desempenho adequado"'. O autor destaca ainda o fato de essa mudança ser realizada pouco antes da implementação da Base Nacional Comum Curricular (BNCC). Em consenso com Freitas (2018c), entendemos que todas essas atitudes, para além de outros fatores, visaram reforçar a necessidade de implementação imediata da reforma da educação brasileira com o chamado "Novo Ensino Médio" e a Base Nacional Comum Curricular (BNCC).

Nesse ínterim, em momento algum se falou em ampliar investimento público na educação. Ao contrário, seguindo as orientações do Banco Mundial, em seu último relatório apresentado ao governo brasileiro intitulado "Um Ajuste Justo: Análise da eficiência e equidade do gasto público no Brasil" (2017), 
que teve como objetivo fazer uma revisão das despesas públicas no país, defende-se que é possível e necessário melhorar a eficiência do ensino, prestar melhores níveis de serviços gastando menos.

\begin{abstract}
A ineficiência do gasto em educação básica no Brasil é elevada e vêm aumentando. Uma Análise Envoltória de Dados (DEA) com dados do PISA da OCDE sobre educação no Brasil e em outros países latino-americanos demonstra que as escolas brasileiras são relativamente ineficientes no uso de recursos (DEA orientada a insumos). Ademais, a ineficiência média aumentou de cerca de 45\% em 2006 para 55\% em 2012. Embora os gastos por aluno tenham aumentado, a maioria das escolas não conseguiu melhorar o desempenho, o que resultou em menor produtividade geral. A eficiência e o desempenho estão correlacionados: as escolas com os melhores resultados são, também, as mais eficientes (Banco Mundial, 2017, p. 124-125).
\end{abstract}

Fica clara aqui a relação essencial entre a atual reforma da educação e o "Novo Regime Fiscal" que congelou todos os gastos públicos mediante a aprovação da Emenda Constitucional no 95/2016. Essa relação não apenas inviabiliza uma educação de qualidade, como conduz a privatização, pois não é possível superar o estado em que se encontra a educação em nosso país sem investimentos públicos. A lógica apresentada pelos Organismos Internacionais está inscrita na lógica do lucro máximo do capital monopolista, sucateia, ressalta a precarização em que se encontra e logo após defende a privatização, relacionando a falácia da eficiência privatista, engrenagem crucial para superar o aprofundamento da decomposição do sistema capitalista atual (Moclate, 2018).

Diante desse contexto de imposições de reformas nas políticas públicas no Brasil, impostas pelos organismos internacionais e ostentadas pelos governos brasileiros ${ }^{3}$, buscamos, neste artigo, analisar as reformas formuladas atualmente para as políticas educacionais, em especial as que versam o ensino médio - a BNCC e a Lei no 13.415/2017, mais conhecida como "Novo Ensino Médio" -, apontando as concepções político-ideológicas que as orientam bem como suas consequências para a educação.

\title{
1 A Base Nacional Comum Curricular
}

Em 2014, inicia-se o debate e, consequentemente, a elaboração da BNCC. Neste período, Dilma Rousseff, então presidente do Brasil, apontou a necessidade de implementação de uma grande reforma no ensino médio, alicerçando uma Base Nacional Comum, assim como definida tanto na Constituição Federal (1988) como na Lei de Diretrizes e Bases da Educação Nacional (LDBEN) - Lei no 9.394/1996, a qual definisse competências, metas e prazos a serem cumpridos pelas instituições de ensino.

Diante do agravamento das contradições entre as frações das classes dominantes no Brasil naquele período e que culminou no impeachment de Dilma Rousseff, a elaboração da BNCC atravessou aceleradas mudanças com a ascensão do governo de Michel Temer (2016-2018).

Tendo em vista as acirradas discussões em torno do ensino médio e objetivando facilitar a imposição da aprovação da BNCC, seus elaboradores optaram por retirar a integralidade da Educação Básica, dividindo-a em educação infantil e ensino fundamental por um lado e do outro o ensino médio. Trata-se, portanto, de um documento que teve a aprovação da primeira etapa facilitada, em 2017, devido a separação entre os níveis de educação, enquanto a segunda etapa só veio ser aprovada no ano subsequente.

Segundo o documento,

A Base Nacional Comum Curricular (BNCC) é um documento de caráter normativo que define o conjunto orgânico e progressivo de aprendizagens essenciais que todos os alunos devem desenvolver ao longo das etapas e modalidades da Educação Básica, de modo a que tenham assegurados seus direitos de aprendizagem e desenvolvimento (Brasil, 2018a, p.7).

Sob a orientação dos Organismos Internacionais, a justificativa para sua implementação parte da necessidade de promover a equidade na aprendizagem, assim os pobres terão asseguradas as aprendizagens mínimas para o desenvolvimento social e econômico, pois é necessário combater a

\footnotetext{
${ }^{3}$ Ver dissertação de mestrado "Imperialismo e Políticas Educacionais para o Ensino Médio no Brasil”, disponível em:

https://repositorio.ufpe.br/bitstream/123456789/35364/4/DISSERTA\%C3\%87\%C3\%83O\%20Larissa $\% 20 \mathrm{dos} \% 2$ OSantos\%20Estev\%C3\%A3o.pdf. Acesso em: 14 fev. 2020.
} 
pobreza. Souza (2010) chama a atenção quanto ao uso do conceito de equidade, pois "diferentemente do conceito de igualdade, a equidade é uma forma de escamotear a desigualdade. A desigualdade seria atributo criado pela incompetência individual, já que todos teriam acesso às oportunidades" (Souza, 2010, p. 180-181). Essa apropriação de conceitos que, à primeira vista, aparentam progressistas tem a finalidade de escamotear as contradições imbuídas nas políticas educacionais.

Segundo Freitas (2018a), essas teses são bases para uma "nova teoria do desenvolvimento social", onde "a questão da pobreza é algo que podemos vencer com uma nova Base Nacional Curricular Comum que, além das habilidades cognitivas, inclua também as habilidades socioemocionais".

Dessa forma, a educação permanece - desde as reformas implementadas na década de 1990, sob orientação dos organismos internacionais, como uma estratégia para concretização da reestruturação produtiva do capital - sendo entendida como o caminho para o desenvolvimento econômico, corroborando o pragmatismo e tecnicismo da Teoria do Capital Humano (TCH) e da Sociedade do Conhecimento ${ }^{4}$, assim como os pilares da educação ${ }^{5}$ apontados pela UNESCO a partir do lema do "aprender a aprender", são eles: Aprender a conviver; Aprender a conhecer; Aprender a fazer; Aprender a ser.

Indica que as decisões pedagógicas devem estar orientadas para o desenvolvimento de competências. Por meio da indicação clara do que os alunos devem "saber" (considerando a constituição de conhecimentos, habilidades, atitudes e valores) e, sobretudo, do que devem "saber fazer" (considerando a mobilização desses conhecimentos, habilidades, atitudes e valores para resolver demandas complexas da vida cotidiana, do pleno exercício da cidadania e do mundo do trabalho), a explicitação das competências oferece referências para o fortalecimento de ações que assegurem as aprendizagens essenciais definidas na BNCC (Brasil, 2018, p. 13).

A partir daí, Freitas (2017) questiona: "Quais direitos: os 60\% definidos na BNCC. Se você tem um "padrão", basta gerenciar a obtenção do padrão. Como na indústria". A política que orientou a elaboração da BNCC é uma política educacional gerencialista. Desde seu início, foi entregue aos grandes empresários educacionais, que tem dominado a política educacional do Ministério da Educação (MEC), organizados no Movimento pela Base, com financiamento da Fundação Lemann.

$\mathrm{Na}$ realidade, a BNCC não passa de um catálogo de competências e habilidades. O governo insiste em afirmar que "A Base não é currículo. Está organizada por referenciais e áreas de conhecimento, e os estados, a partir da Base, vão definir seus currículos, definir como fazer com que os alunos desenvolvam aquelas competências e habilidades específicas de cada área" (Castro apud Freitas, 2018b).

Concordamos com Freitas (2018b), quando este afirma ser esta uma concepção instrumental de currículo, que o restringe ao "como fazer". Entretanto, na forma como está organizada a BNCC, este aspecto também será suprido na elaboração dos materiais didáticos. "Portanto, na prática, a BNCC definiu competências, habilidades (incluindo seu sequenciamento, ano em que devem ser dadas), currículo mínimo, avaliações e materiais didáticos" (Freitas, 2018b), retirando qualquer possibilidade de autonomia docente.

A autonomia no exercício da profissão é um princípio constitucional, contudo são enormes as limitações impostas à autonomia docente pela BNCC, pois:

[...] determina-se de forma centralizada os conteúdos ministrados, condiciona-se a produção do material didático (mina de ouro do mercado editorial), além de nortear a confecção das avaliações para verificação dos índices de desempenho do ensino, na prática, mecanismos de controle, responsabilização e punição dos trabalhadores em educação. Trata-se do modelo de educação para o teste, ou seja, uma escola onde professores resilientes e estudantes obedientes são anulados na sua potência criativa, tornando-se meros reprodutores; no fim, culpabilizados pelo seu "fracasso"

\footnotetext{
${ }^{4}$ Segundo Pereira (2017), a sociedade do conhecimento e da Teoria do Capital Humano podem ser sintetizadas na "lógica de competências e habilidades, corroborando com as exigências de um novo processo de acumulação flexível do modo de produção capitalista e fazendo que os indivíduos busquem competir, ao longo de suas vidas, com o intuito de conseguir uma colocação no disputado mercado de trabalho onde não há postos para todos (Pereira, 2017, p. 6)". Com efeito, o processo educativo passa a ter a função de formar habilidades, atitudes e conhecimentos que garantam uma maior produtividade no trabalho, potencializando a capacidade de trabalho. Assim, a educação deve ser entendida como um investimento como qualquer outro, um capital humano.

5 Ver relatório elaborado pela Comissão Internacional sobre Educação para o século XXI para a UNESCO intitulado "Educação: Um tesouro a descobrir", https://unesdoc.unesco.org/ark:/48223/pf0000109590_por. Acesso em: 29 fev. 2020.
} 
estampado nas avaliações do governo, que ignoram as condições estruturais das escolas, partem de critérios duvidosos e centram fogo no indivíduo (Moclate, 2018).

A BNCC é fundamentada nessa concepção gerencialista, com vistas a padronização. O discurso da equidade na educação, buscando reverter a situação de exclusão dos mais pobres, significa na verdade que, independente das condições concretas, a escola precisa ensinar o currículo mínimo definido na BNCC, sendo punida, principalmente com perdas de "incentivos", caso não tenham um bom desempenho.

A partir disso, cria-se todo um cerco sobre a escola: exames nacionais, produção de material didático e sistemas de ensino, avaliações de professores, normas para formação de professores, etc. A imposição é alinhar a formação de professores, os materiais didáticos, as avaliações e, finalmente, o financiamento aos objetivos da BNCC. Nesse sentido, a Portaria $n^{\circ}$ 1.570/2017 do CNE que institui a Resolução da BNCC afirma que:

Art. 15. As instituições ou redes de ensino podem, de imediato, alinhar seus currículos e propostas pedagógicas à BNCC.

Parágrafo único. A adequação dos currículos à BNCC deve ser efetivada preferencialmente até 2019 e no máximo, até início do ano letivo de 2020.

Art. 16. Em relação à Educação Básica, as matrizes de referência das avaliações e dos exames, em larga escala, devem ser alinhadas à BNCC, no prazo de 1 (um) ano a partir da sua publicação.

Art. 17. Na perspectiva de valorização do professor e da sua formação inicial e continuada, as normas, os currículos dos cursos e programas a eles destinados devem adequar-se à BNCC, nos termos do $\int 8^{\circ}$ do Art. 61 da LDB, devendo ser implementados no prazo de dois anos, contados da publicação da BNCC, de acordo com Art. 11 da Lei no 13.415/2017.

$\int 1^{\circ} \mathrm{A}$ adequação dos cursos e programas destinados à formação continuada de professores pode ter início a partir da publicação da BNCC.

$\int 2^{\circ}$ Para a adequação da ação docente à BNCC, o MEC deve proporcionar ferramentas tecnológicas que propiciem a formação pertinente, no prazo de até 1 (um) ano, a ser desenvolvida em colaboração com os sistemas de ensino.

$[\ldots]$

Art. 19. Os programas e projetos pertinentes ao MEC devem ser alinhados à BNCC, em até 1 (um) ano após sua publicação (Brasil, 2017b, p. 57).

Em consonância, para aferir a qualidade se prevê ainda o Exame Nacional do Magistério do Ensino Básico (ENAMEB) e realinhamento dos exames nacionais à BNCC, sendo o INEP o órgão responsável por todas as avaliações em larga escala do país.

A primeira tarefa de responsabilidade direta da União será a revisão da formação inicial e continuada dos professores para alinhá-las à BNCC. A ação nacional será crucial nessa iniciativa, já que se trata da esfera que responde pela regulação do ensino superior, nível no qual se prepara grande parte desses profissionais. Diante das evidências sobre o peso do professor na determinação do desempenho do aluno e da escola de educação básica, essa é uma condição indispensável para a implementação eficaz da BNCC” (Brasil, 2018, p. 21).

A qualidade da educação é vista apenas como uma questão gerencial, assim o problema está em alinhar tudo à BNCC e teremos uma educação de qualidade. Isso é pura demagogia, pois se trata de controle, regulação, fiscalização e punição das instituições e professores.

Com efeito, a BNCC não pode ser examinada isoladamente, mas como parte das políticas do imperialismo para salvaguardar seu apodrecido sistema de capitalismo burocrático ${ }^{6}$ em decomposição em nosso país. Ao que parece, buscou-se fazer da BNCC uma lei geral para a educação, a qual os sistemas educacionais, as instituições e redes de ensino e formação de professores, além do próprio Ministério da Educação (MEC) devem se ajustar. Essa pressão em questões gerenciais sobre a escola e seus profissionais conduzirá a destruição da escola pública e sua consequente privatização.

"Ver tese de doutorado "Imperialismo e educação no campo: uma análise das políticas educacionais no Estado de
Rondônia https://repositorio.unesp.br/bitstream/handle/11449/101514/souza_mm_dr_arafcl.pdf?sequence=1. Acesso em: 29 fev. 2020. 


\section{O "Novo Ensino Médio" e as Novas DCNEM}

Em meio aos acirrados debates em torno da BNCC para o ensino médio e como meio de garantir que a reforma fosse realizada, aprovou-se a Política de Fomento à Implementação de Escolas de Ensino Médio em Tempo Integral, mais conhecida como "Reforma do Ensino Médio" ou ainda "Novo Ensino Médio", implementada pela Medida Provisória (MP) n ${ }^{\circ} 746 / 2016$, posteriormente convertida na Lei $n^{\circ}$ 13.415/2017. Seu carro chefe é a flexibilização do currículo do ensino médio mediante a oferta de "percursos formativos" e a expansão gradativa da educação em tempo integral na etapa final da educação básica.

Em relação a carga horária, no "Novo Ensino Médio" ela será progressivamente ampliada até atingir 1.400 horas, entretanto deverá atingir 1.000 horas no prazo máximo de 5 anos. Devendo ser mantidos os 200 dias letivos, a carga horária diária deverá aumentar progressivamente até atingir pelo menos 7 horas diárias, ou seja, período em tempo integral.

Como reestruturação curricular, sob a justificativa de "adotar um trabalho voltado para a construção de projeto de vida" dos alunos, passa-se a admitir diferentes percursos formativos, realizados por meio de "itinerários formativos, que deverão ser organizados por meio da oferta de diferentes arranjos curriculares, conforme a relevância para o contexto local e a possibilidade dos sistemas de ensino" (BRASIL, 2017a). Motta e Frigotto (2017) esclarecem as intenções dessa reestruturação curricular:

É nessa seara que a reestruturação do currículo do Ensino Médio é posta como urgente: melhorar o desempenho no IDEB e no PISA, flexibilizando o currículo de forma a facilitar as escolhas das disciplinas que os jovens das classes populares teriam menor dificuldade e, com isso, provavelmente, melhor desempenho nas avaliações em larga escala; desenvolver habilidades e competências que facilitem o ingresso no mercado de trabalho, formal ou informal, ou que proporcionem ocupações que venham a gerar renda - nesse caso, por meio do ensino de empreendedorismo (Motta; Frigotto, 2017, p. 365).

Com isso, a reestruturação do currículo do ensino médio, por um lado, melhora o desempenho nas avaliações em larga escala ao flexibilizar por meio das escolhas de áreas de conhecimento onde se tem menor dificuldade e, por outro, desenvolve habilidades e competências que facilitam o ingresso no mercado de trabalho, dado à adequação as necessidades locais. Diante das intenções postas, fica clara a urgência da aprovação desta reforma.

Assim, o currículo do ensino médio passa a ser composto por componentes curriculares comuns, estabelecidos pela Base Nacional Comum Curricular (BNCC), e cinco itinerários formativos, a saber: linguagens e suas tecnologias; matemática e suas tecnologias; ciências da natureza e suas tecnologias; ciências humanas e sociais aplicadas; formação técnica e profissional.

Os componentes curriculares comuns deverão corresponder a $60 \%$ de todo o ensino médio, sendo apenas a oferta das disciplinas de português e matemática obrigatória nos três anos. Também é obrigatório o ensino do inglês como língua estrangeira, desde o ensino fundamental, sendo facultativa a oferta de outras línguas. As demais disciplinas devem, obrigatoriamente, ser incluídas, mas não necessita perpassar todo o percurso. O "Novo Ensino Médio" aponta ainda a carga horária máxima para esses componentes curriculares comuns que é 1.800 horas para os três anos do ensino médio, entretanto não estabelece uma carga horária mínima, o que, segundo Kuenzer (2017), pode dar autonomia as instituições para estabelecerem uma carga horária menor.

Já o restante da carga horária do ensino médio, isto é, os $40 \%$ que não serão dedicados aos conteúdos da BNCC, deverão ser preenchidos com itinerários formativos "organizados por meio da oferta de diferentes arranjos curriculares" (Brasil, 2017), assim, "dependendo da duração total do curso, o caminho escolhido terá duração diferente, podendo a carga horária destinada à educação técnica e profissional variar entre 25 e 62\% do total de duração do curso" (Kuenzer, 2017, p. 335).

De acordo com Kuenzer (2017), essa modalidade de ensino é um momento onde o jovem está se preparando para fazer suas escolhas e, portanto, necessita da maior interação possível com as diferentes áreas. A organização curricular imposta pela reforma aponta o contrário, uma hierarquização das disciplinas e uma escolha precoce por uma área de estudo, isso fragmenta a formação dos sujeitos, sobrepondo-se a proposta de formação da integralidade da pessoa humana que vinha sendo discutida nas Diretrizes Curriculares Nacionais para o Ensino Médio (DCNEM). 
Além disso, a oferta de vários desses itinerários, apresentados como oportunidade de escolha para os jovens, não é obrigatória às redes de ensino. Estas poderão ofertar apenas um itinerário, desde que leve em conta o contexto e as possibilidades do sistema de ensino. Isso nos aponta duas questões: restrição das possibilidades de escolha pelos alunos e precarização. Sobre a primeira, Kuenzer (2017, p. 335) afirma que:

A oferta de quantos e quais itinerários formativos será definida pelos sistemas de ensino, segundo suas condições concretas, o que levará à restrição das possibilidades de escolha pelo aluno, ou seja, ao enrijecimento. Da mesma forma, o aluno pode cursar mais de um itinerário, desde que haja vaga (dependendo da carga horária, isso só será possível na forma subsequente).

Motta e Frigotto (2017, p. 368) complementam apontando que "Não será questão de 'livre escolha', como propalam os reformadores, mas compulsória, pois será o caminho de cumprir com a carga horária obrigatória [...]”. Em relação a precarização, os autores afirmam que essa reforma do ensino médio

\begin{abstract}
* retroage à Lei no 5.692/1971, reforma da educação dos tempos da ditadura empresarial militar com uma profissionalização precária frente às realidades dos estados [...] quando houver, a ampliação do que denomina de escola de tempo integral em condições infraestruturais precarizadas. Nessas condições dadas, cada escola vai ofertar a educação profissional que couber em seu orçamento (Motta; Frigotto, 2017, p. 368).
\end{abstract}

Nessa lógica, teremos aqui dois problemas, a precarização em relação à estrutura e a precarização em relação à qualidade.

Resgata o Decreto $n^{\circ}$ 2.208/19977 ao afirmar que "o ensino médio poderá ser organizado em módulos e adotar o sistema de créditos com terminalidade específica" (BRASIL, 2017a) e abre possibilidade para reconhecer competências e firmar convênios com instituições de ensino tanto presencial como a distância, essa flexibilização possibilita que competências e cursos realizados em outros espaços sejam validados. Nessa perspectiva, Motta e Frigotto (2017) destacam que essa nova organização curricular:

Retoma, de forma pior, o Decreto no 2.208/1996, que já aprofundava a dualidade estrutural entre educação profissional e educação básica. O anúncio do Medio-Tec pelo MEC indica, de forma clara, a incorporação do Pronatec no Ensino Médio regular. Uma comprovação inequívoca de que se trata de uma contrarreforma destinada aos filhos da classe trabalhadora. Também uma confissão explícita de que o MEC assume, de fato, uma divisão classista da educação (Motta Frigotto, 2017, p. 368).

Longe de representar uma ampliação de oportunidades, "os conhecimentos científicos produzidos historicamente pela humanidade são postos em segundo plano, adquire um caráter instrumental e pragmático, definindo-se como "conteúdos, os saberes atitudinais, no campo dos valores, das competências, habilidades e relações interpessoais" (Rabelo; Segundo; Jimenez, 2009, p. 10), voltados a valorização do capital e às demandas do mercado, dispersando as práticas educativas por diferentes espaços, sem a exigência de rigor teórico.

Para além da desqualificação da aprendizagem, entre estes itinerários, figura ainda a desqualificação profissional, com a possibilidade de oferta de educação técnica e profissional exercida por profissionais dotados de "notório saber". Se a oferta de todos os itinerários não é obrigatória e dependem das condições do sistema de ensino, "a tendência será reduzir a oferta, privilegiando as áreas que dependem menos de docentes qualificados e de recursos materiais e tecnologias mais sofisticadas" (Kuenzer, 2017, p. 336), pois serão menos dispendiosos. Para Kuenzer,

[...] a reforma resolveu, pelo menos, dois grandes problemas para os sistemas de ensino: a falta de professores para várias disciplinas e a dificuldade para resolver a precariedade das condições

\footnotetext{
7 “O Decreto n” 2.208/1997 instituiu a Reforma do Ensino Médio e da Educação Profissional ao separar a oferta da educação básica - principalmente o ensino médio - do ensino técnico, passando este a ser ofertado de forma complementar, paralela ou sequencial. Essa reforma garantiu a livre atuação das instituições privadas no ensino técnico, o que gerou uma enorme expansão da oferta privada de cursos profissionalizantes de nível básico, que, apesar do caráter formativo profissional, são cursos sem vinculação com conhecimento científico, de curta duração e sem garantia ou avaliação da qualidade” (Estevão, 2019, p. 83).
} 
materiais das escolas, principalmente em termos de laboratórios, bibliotecas, equipamentos de informática, acesso à internet e construção de espaços para atividades culturais e esportivas (Kuenzer, 2017, p. 336).

Por fim, a lei da reforma do ensino médio prevê ainda que os "currículos dos cursos de formação de docentes terão por referência a Base Nacional Comum Curricular" (Brasil, 2017a). Reforçando o papel do docente enquanto mediador ou facilitador da aquisição do conhecimento, sua formação deve centrar-se no oferecimento do "kit de sobrevivência docente" (Libâneo, 2012, p. 20), que o transforma no professor tarefeiro, dador de aulas, seguidor de cartilha, visando a diminuição dos custos com formação, capacitação e salário.

Em 2018, o Conselho Nacional de Educação (CNE) promulgou as novas DCNEM, a fim de adequá-las a reforma em vigor.

O Parecer do CNE/CEB n ${ }^{\circ}$ 3/2018 atrelado às DCNEM em questão, retoma os fundamentos das primeiras Diretrizes para o Ensino Médio publicadas em 1998 justificando que “suas definições normativas [agora] permanecem absolutamente válidas, razão pela qual está sendo retomado no presente Parecer" (BRASIL, 2018b, p. 4), apesar de em 2012 elas terem sido atualizadas por estarem defasadas após as mudanças tanto na legislação brasileira como em relação às exigências educacionais decorrentes da aceleração da produção do conhecimento, acesso à informação, alterações no mundo trabalho e dos interesses dos sujeitos dessa etapa educacional (Brasil, 2013).

Enquanto que a Resolução do CNE/CEB no 3/2018, ao explicitar o conteúdo da nova organização do ensino médio, retoma aspectos presentes nas DCNEM de 2012, ao elencar, entre os princípios específicos para o ensino médio a "formação integral do estudante", "projeto de vida como estratégia de reflexão", a "pesquisa como prática pedagógica", etc. Vemos aqui de forma explicita a artimanha de aglutinar conceitos e categorias antagônicas das classes populares e liberais; incluir maior número possível das demandas; contemplar o maior campo conceitual possível, a fim de se mostrar democrático.

A resolução prevê ainda a flexibilização do currículo, onde as:

[...] atividades realizadas a distância podem contemplar até 20\% (vinte por cento) da carga horária total, podendo incidir tanto na formação geral básica quanto, preferencialmente, nos itinerários formativos do currículo [...] podendo a critério dos sistemas de ensino expandir para até 30\% (trinta por cento) no ensino médio noturno (Brasil, 2018c, p. 11).

Segundo Kuenzer (2017), esse princípio de flexibilização do currículo, inclusive com esse fomento à educação distância, insere-se em um quadro conceitual mais amplo, o da aprendizagem flexível que é reflexo do atual regime de produção vigente, a Acumulação Flexível.

A aprendizagem flexível é “[...] concebida como resultado de uma metodologia inovadora, que articula o desenvolvimento tecnológico, a diversidade de modelos dinamizadores da aprendizagem e as mídias interativas [...]" (Kuenzer, 2017, p. 337). Nesse contexto, ela se justifica dada a necessidade de expandir o ensino a fim de atender as demandas de uma sociedade mais exigente e competitiva. A autora chama a atenção para a modificação das formas de participação do aluno, no que tange a metodologia:

Do ponto de vista metodológico, na concepção da aprendizagem flexível, a forma de participação do aluno nessa proposta muda bastante: de espectador, passa a ser sujeito de sua própria aprendizagem, o que exigirá dele iniciativa, autonomia, disciplina e comprometimento. Nas modalidades de aprendizagem flexível disponibilizadas, ele fará seu próprio horário de estudo, estabelecerá as condições e o ritmo em que estudará, segundo seu perfil e suas possibilidades. Em tese, ao gerenciar seus tempos e espaços, aprenderia a aprender, sozinho ou em colaboração, o que conduziria a um melhor aproveitamento; e, nas práticas colaborativas, deixaria de ser isolado em suas tarefas e leituras, de modo a também superar posturas individualistas (Kuenzer, 2017, p. $337-$ 338).

Observamos a ênfase dada ao modelo neoescolanovista, com o lema aprender a aprender, que além de pragmático, responsabiliza e culpabiliza os sujeitos pelas desigualdades sociais ${ }^{8}$.

Outras modificações importantes são apresentadas, como a emissão de certificados de conclusão do ensino médio pelas redes de ensino evidenciando os itinerários formativos cursados, a admissão de

\footnotetext{
${ }^{8}$ Ver livro "História as ideias pedagógicas no Brasil" de Dermeval Saviani.
} 
profissionais que tenham cumprido "programas de complementação pedagógica" para docência na educação básica, a adequação do ENEM à BNCC e ao novo ensino médio mediante prova escolhida pelo aluno "de acordo com a área vinculada ao curso superior que pretende cursar", etc (Brasil, 2018c, p. 1116).

Fica claro que as atuais reformas para a educação brasileira estão dentro do projeto para salvaguardar o capitalismo burocrático do Estado brasileiro, expresso na retirada dos direitos democráticos conquistados pelas classes populares, com o congelamento dos recursos públicos para a educação e saúde, flexibilização das leis trabalhistas e propostas de reforma da previdência. Está expressa ainda na rigidez quanto à hierarquização das disciplinas, apresentando obrigatoriedade apenas as recomendadas pelos organismos internacionais, negando os conhecimentos científicos acumulados pela humanidade às classes populares, bem como nas parcerias público-privadas utilizadas como estratégia de privatização do ensino médio.

[...] trata-se de uma contrarreforma que expressa e consolida o projeto da classe dominante brasileira em sua marca antinacional, reparao, antieducação pública, em suas bases políticoeconômicas [...], que condena gerações ao trabalho simples e nega os fundamentos das ciências que permitem aos jovens entender e dominar como funciona o mundo das coisas e a sociedade humana. Uma violência cínica de interdição do futuro dos filhos da classe trabalhadora por meio da oficialização da dualidade intensificada do Ensino Médio e de uma escola esvaziada [...] (Mota; Frigotto, 2017, p. 369).

É evidente que essa reestruturação curricular vem reforçar o caráter de classe da educação brasileira. A sociedade capitalista reconstrói a diferença entre as escolas das elites, voltadas para a formação intelectual, e as escolas para as massas, que são limitadas à escolarização básica ou se restringem a determinada habilitação profissional (Saviani, 1994), isso expressa a dualidade por trás da democratização do ensino e aprendizagem. Entretanto, essa dualidade não é uma questão pedagógica ou gerencial, mas a materialização do caráter de classe da educação.

\section{Considerações Finais}

O caminho que essas reformas educacionais têm trilhado, recorrendo a investimento em capital humano visando maior produtividade; precarização do ensino com foco em aprendizagens mínimas, com flexibilização e esvaziamento científico do currículo, sendo este substituído por habilidades socioemocionais e competências de caráter instrumental e pragmático; avaliação com foco em resultados de desempenho; responsabilização docente, inclusive com caráter punitivo; a intromissão do capital privado (privatização) que dá ênfase aos conceitos de eficiência, eficácia, produtividade, qualidade total, não objetiva o desenvolvimento humano em sua integralidade, não servem às massas trabalhadoras, às classes populares. Esse tipo de concepção ideológica, político-pedagógica está muito longe de atender as necessidades das classes populares, ao contrário, esse tipo de educação tem sido "o processo mediante o qual as classes dominantes preparam na mentalidade e na conduta das crianças as condições fundamentais da sua própria existência" (Ponce, 2015, p. 205).

Nos países de capitalismo burocrático, como é o caso do Brasil, destacamos que se desenvolve uma linha burocrática no campo ideológico que consiste no processo para moldar todo o povo na concepção e ideias políticas que o servem, sendo as políticas educacionais a expressão concentrada desta linha. Contrapondo-se a ela, temos o caminho democrático que busca transformar a realidade do ensino público, sendo necessário para tanto destruir a educação dualista que opõe os que "pensam" e os que "fazem", o trabalho intelectual do trabalho manual da educação burguesa. Devemos ter uma atitude marxista e travar lutas dentro da escola burguesa, transformando-a em trincheira da luta de classes, como uma estratégia para a transformação da educação.

Em nosso país é necessário romper as amarras do imperialismo e as bases do capitalismo burocrático. É necessário lutar para transformar a realidade do ensino público, defender uma educação a serviço das classes populares, combinada com o trabalho produtivo, formando o ser humano na sua integralidade, isso é seguir o caminho democrático, é parte da revolução democrática.

As classes populares devem elevar sua consciência de classe para atuar ativamente na construção de possibilidades de uma nova escola, defender o ensino público e a serviço do povo, uma educação popular e científica e não por ditos pensadores representantes da ideologia burguesa e perversa do capital. 
Diante de avançada crise econômica, política, moral e social, observamos o agravamento de todas as contradições fundamentais no mundo, uma agudização da luta de classes, um cenário crescente de reacionarização do Estado, mas que impulsiona ações cada vez maiores e mais consequentes de resistência popular em defesa dos direitos democráticos conquistados pelas classes populares.

No cenário político atual, com o governo Bolsonaro, temos acompanhado diversas reformas que estão dentro do projeto para salvaguardar o apodrecido capitalismo burocrático do Estado brasileiro, expresso na continuação do esfacelamento de todos os direitos democráticos de forma mais enfática. $\mathrm{Na}$ educação, temos visto os grandes cortes de verbas para conter, segundo o gerente de plantão, "a balbúrdia", ou seja, onde professores e alunos estão empenhados em defender o direito à educação pública, gratuita e de qualidade, a crescente censura e criminalização, desconsiderando o processo pedagógico e a formação crítica dos estudantes, impondo valores fascistas, concepções irracionais e obscurantistas. Essa é mais uma expressão da ameaça à liberdade democrática de ensino no país, que busca conter a ideologia comunista.

As classes dominantes continuam subestimando a resistência das classes populares. É preciso nos mobilizar de forma ampla, radical e consequente para a luta contra as políticas educacionais do imperialismo que estão sendo implementadas em nosso país, contra a precarização e sucateamento do ensino público, contra as estruturas de classe do capitalismo burocrático, atrasado e semifeudal, que se expressão na educação. É necessário elevar a nossa consciência de classe e atuar ativamente na defesa da educação pública, gratuita, democrática, científica e a serviço do nosso povo.

\section{Referências}

Banco Mundial [Bm]. (2017). Um Ajuste Justo: Análise Da Eficiência E Equidade Do Gasto Público No Brasil. 2017.

Brasil. Lei No 9.394, De 20 De Dezembro De 1996. 1996. Disponível em: http://www.planalto.gov.br/Ccivil_03/Leis/L9394.Htm. Acesso em: 23 Nov. 2018.

Brasil. Decreto No 2.208, De 17 De Abril De 1997. 1997. Disponível em: http://www2.camara.leg.br/Legin/Fed/Decret/1997/Decreto-2208-17-Abril-1997-445067-

Publicacaooriginal-1-Pe.Html. Acesso em: 23 Nov. 2018.

Brasil. Parecer Cne/Ceb $\quad N^{o} \quad 15 / 1998.1998 . \quad$ Disponível em: http://portal.mec.gov.br/Seb/Arquivos/Pdf/Par1598.Pdf. Acesso em: 23 Nov. 2018.

Brasil. Diretrizes Curriculares Nacionais Da Educação Básica. Brasília: Mec, 2013.

Brasil. Emenda Constitucional No 95, De 15 De Dezembro De 2016. 2016. Disponível em: http://www.planalto.gov.br/Ccivil_03/Constituicao/Emendas/Emc/Emc95.Htm. Acesso em: 29 Jul. 2019.

Brasil. Lei No 13.415, De 16 De Fevereiro De 2017. 2017a. Disponível em: http://www.planalto.gov.br/Ccivil_03/_Ato2015-2018/2017/Lei/L13415.Htm. Acesso em: 23 Nov. 2018.

Brasil. Portaria No 1.570, De 21 De Dezembro De 2017. 2017b. Disponível em: http://portal.mec.gov.br/Docman/Dezembro-2017-Pdf/78631-Pcp015-17-Pdf/File. Acesso em: 23 Nov. 2018.

Brasil. Base Nacional Comum Curricular: Educação É A Base. 2018a. Disponível em: http://basenacionalcomum.mec.gov.br/Wp-

Content/Uploads/2018/06/Bncc_Ensinomedio_Embaixa_Site_110518.Pdf. Acesso em: 06 Dez. 2018. 
Brasil. Parecer Cne/Ceb $\quad \mathrm{N}^{\circ}$ 3/2018. 2018b. Disponível em: http:/ / portal.mec.gov.br/Index.Php?Option=Com_Docman\&View=Download\&Alias=102311 Pceb003-18\&Category_Slug=Novembro-2018-Pdf\&Itemid=30192. Acesso em: 29 Jul. 2019.

Brasil. Resolução No 3, De 21 De Novembro De 2018. 2018c. Disponível em: http://www.in.gov.br/Materia/-/Asset_Publisher/Kujrw0tzc2mb/Content/Id/51281622. Acesso em: 29 Jul. 2019.

Delors, Jacques. Educação: Um Tesouro A Descobrir. Unesco, 2010.

Estevão, Larissa Dos Santos. Imperialismo E Políticas Educacionais Para O Ensino Médio No Brasil. 2019. Dissertação (Mestrado) - Universidade Federal De Pernambuco, Recife, 2019.

Freitas, Luiz Carlos De. Bncc: Uma Base Para O Gerencialismo-Populista. 2017. Disponível em: https://avaliacaoeducacional.com/2017/04/07/Bncc-Uma-Base-Para-O-Gerencialismo-Populista/.

Acesso em: 23 Nov. 2018.

Freitas, Luiz Carlos De. A Bncc E A “Salvação" Dos Pobres Pela Resiliência. 2018a. Disponível em: https://avaliacaoeducacional.com/2018/03/08/A-Bncc-E-A-Salvacao-Dos-Pobres-Pela-Resiliencia/. Acesso em: 23 Nov. 2018.

Freitas, Luiz Carlos De. Mec: Um Estranho Conceito De "Currículo" (Atualizado). 2018b. Disponível em: https://avaliacaoeducacional.com/2018/03/15/Mec-Um-Estranho-Conceito-De-Curriculo/. Acesso em: 23 Nov. 2018.

Freitas, Luiz Carlos De. Saeb 17: Ajuste Antecipado Para A Bncc?. 2018c. Disponível em: https://avaliacaoeducacional.com/2018/09/05/Saeb-17-Ajuste-Antecipado-Para-A-Bncc/. Acesso em: 23 Nov. 2018.

Inep. Saeb 2017 Revela Que Apenas 1,6\% Dos Estudantes Brasileiros Do Ensino Médio Demonstraram Níveis De Aprendizagem Considerados Adequados Em Língua Portuguesa. 2018. Disponível em: http://Portal.Inep.Gov.Br/Artigo/-/Asset_Publisher/B4aqv9zfy7bv/Content/Saeb-2017-Revela-QueApenas-1-6-Dos-Estudantes-Brasileiros-Do-Ensino-Medio-Demonstraram-Niveis-De-AprendizagemConsiderados-Adequados-Em-Lingua-Portug/21206. Acesso em: 23 Nov. 2018.

Kuenzer, Acacia Zeneida. Trabalho E Escola: A Flexibilização Do Ensino Médio No Contexto Do Regime De Acumulação Flexível. Campinas: Educação E Sociedade, 2017, V. 38, N. 139, P. 331-354. Disponível em: http://www.scielo.br/Pdf/Es/V38n139/1678-4626-Es-38-139-00331.Pdf. Acesso em: 03 Mar. 2020.

Libâneo, José Carlos. O Dualismo Perverso Da Escola Pública Brasileira: Escola Do Conhecimento Para Os Ricos, Escola Do Acolhimento Social Para Os Pobres. São Paulo: Educação E Pesquisa, 2012, V. 38, N. 1, P. 13-28. Disponível em: http://www.Scielo.Br/Pdf/Ep/V38n1/Aop323.Pdf. Acesso em: 03 Mar. 2020.

Mariátegui, José Carlos. Sete Ensaios De Interpretação Da Realidade Peruana. 2. Ed. São Paulo: Expressão Popular, 2010.

Moclate. Bncc E ‘Reforma’ Do Ensino Médio: Duas Faces Do Mesmo Desmonte. 2018. Disponível em: https://anovademocracia.com.br/No-216/9564-Bncc-E-Reforma-Do-Ensino-Medio-Duas-Faces-DoMesmo-Desmonte. Acesso em: 23 Nov. 2018.

Motta, Vânia Cardoso Da; Frigotto, Gaudêncio. Por Que A Urgência Da Reforma Do Ensino Médio? Medida Provisória No 746/2016 (Lei No 13.415/2017). Campinas: Educação E Sociedade, 2017, V. 38, N. 139, P. 355-372. Disponível em: http://www.scielo.br/Pdf/Es/V38n139/1678-4626-Es-38-13900355.Pdf. Acesso em: 03 Mar. 2020. 
Ponce, Aníbal. Educação E Luta De Classes. 24 Ed. São Paulo: Cortez, 2015.

Rabelo, Jackline; Segundo, Maria Das Dores Mendes; Jimenez, Susana. Educação Para Todos E Reprodução Do Capital. Trabalho Necessário, 2009, Ano 7, N. 9. Disponível em: http://periodicos.uff.br/Trabalhonecessario/Article/View/6097/5062. Acesso em: 03 Mar. 2020.

Saviani, Dermeval. O Trabalho Como Princípio Educativo Frente As Novas Tecnologias. In: Ferreti, Celso João (Org.) Et Al. Novas Tecnologias, Trabalho E Educação: Um Debate Multidisciplinar. Petrópolis: Vozes, 1994.

Saviani, Dermeval. História As Ideias Pedagógicas No Brasil. 4. Ed. Campinas, Sp: Autores Associados, 2013.

Souza, Marilsa Miranda De. Imperialismo E Educação No Campo: Uma Análise Das Políticas Educacionais No Estado De Rondônia A Partir De 1990. 2010. Tese (Doutorado Em Educação Escolar) - Universidade Estadual Paulista, Araraquara, SP, 2010.

\section{Sobre a Autora}

\section{LARISSA DOS SANTOS ESTEVÃO}

iD ORCID: https://orcid.org/0000-0003-1035-1587

Mestre em Educação pela Universidade Federal de Pernambuco. Pedagoga pela Universidade Federal de Alagoas. Integrante do Grupo Gestor (Pesquisa em Gestão da Educação e Políticas do Tempo Livre). Docente do curso de Pedagogia da Faculdade Pitágoras de Maceió.

E-mail: laure_estevao@hotmail.com.

Enviado em: 13 set. 2020.

Aprovado em: 15 fev. 2021. 